\title{
The Role of Preprocedure Screening of SARS-CoV-2 Infection: A Tertiary Care Medical Center Analysis
}

\author{
Catarina Correia ${ }^{a}$ Nuno Almeida ${ }^{a, b}$ Pedro Figueiredo ${ }^{a, b}$ \\ ${ }^{a}$ Department Gastroenterology, Centro Hospitalar e Universitário de Coimbra, Coimbra, Portugal; \\ ${ }^{b}$ Faculty of Medicine, University of Coimbra, Coimbra, Portugal
}

\section{Keywords}

SARS-CoV-2 infection · Screening · Gastroenterology

\section{Abstract}

Purpose: This study aimed to understand the prevalence of asymptomatic COVID-19 infection among patients undergoing endoscopic procedures at a tertiary care hospital. The results allow prediction of the magnitude of cases which this endoscopic service might witness in the next months and planning of future actions accordingly. Methods: This retrospective study was conducted in the gastroenterology department of a large urban tertiary care medical center from October 15, 2020, to November 15, 2020. In this institution, all patients proposed for endoscopic procedures under deep sedation must be submitted to reverse transcription polymerase chain reaction (RT-PCR) for SARS-CoV-2 (severe acute respiratory syndrome coronavirus 2 ) detection. These results were thoroughly reviewed. Results: In the 1-month period, a total of 833 different procedures were done in 833 patients admitted to the endoscopy unit. Of these, $167(20 \%)$ were submitted to nasal swab for SARS-CoV-2. Only $1(0.6 \%)$ was positive for this infection, and her procedure was postponed. This RT-PCR-positive patient was not symptomatic for COVID-19 infection at the time of preprocedure screening. She had no positive contacts for COVID-19 and had not traveled outside the country. Conclusion: We found that the proportion of patients proposed for an endoscopic intervention who were asymptomatic carriers of SARS-CoV-2 was low. However, only one fifth of patients were tested and, considering the proportion of $0.6 \%$, it is reasonable to consider that exposure of healthcare workers and other patients can occur. So, all prevention measures must be strictly followed. However, the cost-benefit of an universal testing policy must be proven.

(C) 2021 Sociedade Portuguesa de Gastrenterologia Published by S. Karger AG, Basel

\section{Rastreio da infeção por SARS-CoV-2 \\ pré-procedimentos - análise de um centro terciário \\ Palavras Chave \\ Infecção por SARS-CoV-2 · Rastreio · Gastrenterologia}

\section{Resumo}

Objetivos: Este estudo teve como objetivo avaliar a prevalência de infeção assintomática por COVID-19 em pacientes submetidos a procedimentos endoscópicos num hospital terciário. Os resultados permitem prever a magnitude dos casos que este serviço poderá testemunhar karger@karger.com www.karger.com/pjg

Karger $\stackrel{\text { ' }}{5}$

BOPEN ACCESS (c) 2021 Sociedade Portuguesa de Gastrenterologia Published by S. Karger AG, Basel

This is an Open Access article licensed under the Creative Commons Attribution-NonCommercial-4.0 International License (CC BY-NC) (http://www.karger.com/Services/OpenAccessLicense), applicable to the online version of the article only. Usage and distribution for commercial purposes requires written permission.
Correspondence to:

Catarina Correia,11265@chuc.min-saude.pt 
nos próximos meses e assim planear ações futuras. Métodos: Estudo retrospetivo realizado no serviço de Gastroenterologia de um centro terciário, de 15 de outubro de 2020 a 15 de novembro de 2020. Nesta instituição todos os pacientes propostos para procedimentos endoscópicos sob sedação profunda devem ser submetidos a RTPCR para deteção de SARS-CoV-2. Esses resultados foram analisados. Resultados: No período de um mês, foram realizados 833 procedimentos em 833 pacientes admitidos na unidade de endoscopia. Destes 167 (20\%) foram submetidos à realização de zaragatoa nasal para deteção de SARS-CoV-2. Apenas um $(0,6 \%)$ foi positivo para a infeção e seu procedimento foi adiado. Este paciente RT-PCR positivo era assintomático para infeção por COVID-19 no momento da triagem pré-procedimento, não teve contatos positivos para COVID-19 e não realizou nenhuma viagem para fora do país. Conclusão: Verificamos que a proporção de pacientes propostos para intervenção endoscópica portadores assintomáticos de SARS-CoV-2 foi baixa. Porém, apenas um quinto dos pacientes foi testado e considerando a proporção de $0.6 \%$ é razoável considerar que pode ocorrer exposição de profissionais de saúde e outros pacientes. Portanto, todas as medidas de prevenção devem ser rigorosamente seguidas. No entanto, o custobenefício de uma política universal de testes deve ser comprovado.

( 2021 Sociedade Portuguesa de Gastrenterologia Publicado por S. Karger AG, Basel

\section{Introduction}

SARS-CoV-2 (severe acute respiratory syndrome coronavirus 2) is a 2020 pandemic which has brought about changes and demands to the existing infrastructure of healthcare setups both in terms of diverting specialized care to SARS-CoV-2 virus infection (COVID-19) patients and prevention of infection of healthcare professionals through rigorous protocols in personal protective equipment (PPE) use.

The Centers for Disease Control and Prevention reported 228,503 cases of COVID-19 infection and 822 deaths amongst US healthcare workers (HCW) as of November 20, 2020 [1].

Considering the great risk of transmission between patients and HCW, healthcare institutions face enormous challenges in balancing patients' needs and simultaneously the safety of the HCW.

All around the world, COVID-19 has had a tremendous economic impact. Hospitals were forced to cut down on elective procedures, affecting patient care and also the revenue generated. Globally, approximately 28.4 millions of elective procedures have been canceled due to disruption by the pandemic [2]. Providing ongoing hospital services in a smooth and effective manner while keeping patients and HCW safe a priority. More than 6 months into the pandemic, governments around the world have been discussing how to restart elective procedures safely, ensuring the protection of both the providers and the patients.

Regarding endoscopy units, multiple guidelines have been published, with a major focus on screening and precautions for patients undergoing endoscopy. Different strategies for a return to normalcy are under discussion, aimed at protecting HCW and patients from infection [3]. One question that has remained largely unanswered in all guidelines is whether we should routinely test for COVID-19 before elective and semi-urgent endoscopic procedures in order to increase the safety of the hospital environment. Another challenge is the signaling of potential COVID-19 patients since this disease can present in the pre- or asymptomatic transmission phase and identification of patients with such conditions may be quite difficult.

Hence, elective testing before surgeries or some elective interventions like endoscopic procedures has been proposed by international authorities based on the local transmission rate, the type of procedure performed, and the amount of presumed exposure [4]. In June 2020 some medical research proposed that testing for COVID-19 should be done for asymptomatic patients coming for elective surgeries like neurosurgery, ear-nose-throat surgery, and dental procedures and for nonsurgical interventions like bronchoscopy, upper gastrointestinal endoscopy, and dialysis [5]. Infection prevention strategies to protect $\mathrm{HCW}$ in the endoscopy unit during the COVID-19 pandemic are currently under intense discussion.

This study aimed to understand the prevalence of asymptomatic COVID-19 infection among patients undergoing endoscopic procedures at a tertiary care hospital. The results allow prediction of the magnitude of cases which this endoscopic service might witness in the next months and planning of future actions accordingly.

\section{Methods}

This retrospective study was conducted at a large urban tertiary medical care center (Gastroenterology Department, Coimbra University Hospital Centre, Portugal) from October 15, 2020, to November 15, 2020.
Correia/Almeida/Figueiredo 
Before any procedure, each outpatient had to answer an oral COVID-19 questionnaire, which included questions related to their systemic health status (fever, cough, myalgia, headache, and throat pain), their recent travel history, and any history of contact with a COVID-19-positive patient or symptomatic patient.

At the end of March 2020, mandatory universal screening for COVID-19 was initiated at our institution for patients undergoing endoscopic procedures under deep sedation administered by anesthesiologists according to the rules implemented by anesthesiology societies and applied by our hospital. This screening was done using a lab-developed reverse transcription polymerase chain reaction (RT-PCR) assay to detect SARS-CoV-2 from a nasopharyngeal swab. It was performed within $72 \mathrm{~h}$ of the scheduled procedure in every patient with the abovementioned conditions. All patients who needed to become hospitalized after a procedure were also submitted to a SARS-CoV-2 screening.

In all endoscopic procedures, regardless of whether the patient was tested or not, the level of protection and the PPE used were the same and at our institution all patients were considered high risk following the current recommendations [6].

Statistical analyses were performed using SPSS Statistics software (version 23.0; IBM).

Results

During 1 month, a total of 833 different procedures were done in 833 patients (male sex, $n=486 ; 58.3 \%$; average age $63.5 \pm 11.6$ years, range $22-91$ years). Overall, $161(19.3 \%)$ were urgent procedures and $672(80.7 \%)$ were elective ones. Within the latter, 139 (20.7\%) were performed under deep sedation in patients with a preprocedure screening of SARS-CoV-2 infection performed within $72 \mathrm{~h}$ of the planned procedure. Only 1 patient $(0.7 \%)$, with echoendoscopy scheduled to clarify probable biliary lithiasis, showed a RT-PCR positive for COVID-19. In another patient, with colonoscopy planned for polypectomy, the preprocedure screening of SARS-CoV-2 infection was inconclusive, and consequently the colonoscopy was not performed. However, when the test was repeated it came back negative. In both cases, the patients were asymptomatic, had no positive contacts for COVID, and had not traveled outside the country.

Additionally, 28 patients (4\%) who needed to be hospitalized after an endoscopic intervention were also submitted to COVID-19 screening, which was negative in all of them.

Globally, 167 out of the 833 (20\%) patients proposed for endoscopic interventions were screened and only 1 was positive. Of the 666 (80\%) untested patients, we were not aware of any case of SARS-CoV-2 infection in the 14 days following the endoscopic procedure.

The Role of Preprocedure Screening of SARS-CoV-2 Infection
At the time this paper was written, there were no COVID-19 infections among the endoscopy unit personnel related to their professional interventions, or a history of infections associated with interventions in our endoscopy units.

\section{Discussion}

Many recommendations have been made regarding the circuit of patients in hospital units, the adequate time and proper cleaning protocols, and the importance of adequate ventilation in the rooms [7]. All rooms visited by a possible or confirmed case of COVID-19 should be naturally or mechanically ventilated, depending on the setting [8]. When a mechanical ventilation system is in place, the air should be exchanged 6-10 times per hour, depending on the national standards $[9,10]$. In those cases where mechanical ventilation is not available, the rooms need to be naturally ventilated at regular intervals, with the required ventilation time depending on the size of the room, the number of windows and doors that can be opened, the outside temperature, and the airflow/wind $[10,11]$.

The notification circuit for COVID patients in a hospital environment must be linked to the Program for the Prevention and Control of Infection and Resistance to Antimicrobials (PPCIRA). In addition, there is the TRACE COVID platform, which is accessible to all health professionals and makes possible the registration of $\mathrm{CO}$ VID patients; this creates a bridge with public health for a control and close monitoring of COVID patients or suspicious cases [12]. The using of such tools makes the identification of secondary cases much quicker, leading to a possible interruption of disease transmission chain.

Concern regarding the spread of COVID-19 by asymptomatic patients prompted many centers to undertake preprocedural SARS-CoV-2 screening. However, this approach varies by endoscopic center due to the lack of consensus [13]. In our unit, we follow Portuguese general health directorate (DGS) norm 019/2020, which establishes the performance of tests in all anesthetic procedures given the possible need for additional interventions such as endotracheal intubation/extubation, manual ventilation, noninvasive ventilation, and high-flow oxygen therapy [14].

A systematic review by Jackson et al. [15] presents a group of procedures with a poor consensus when classifying it as aerosol-generating procedures. In 4 groups of procedures (oral and dental, upper GI endoscopy, thoracic surgery and procedures, and nasopharyngeal/oro-

GE Port J Gastroenterol 2022;29:31-37 
pharyngeal swabbing), there appeared to be substantial disagreement among sources with $<80 \%$ consensus. This lack of a consensus and the fact that endoscopic procedures are not considered in this standard as high-risk, aerosol-generating procedures have been the subject of some debate and disagreement between the different gastroenterology societies. This normative has generated concern among health professionals working in this area, since they might be at an increased risk, which is being devalued. In a joint statement, Portuguese societies of endoscopy and gastroenterology argued that the evidence is clear that digestive endoscopy procedures are aerosol generators. Thus, they considered that among the aerosol-generating procedures described in the DGS standard, such as "endotracheal intubation/extubation, manual ventilation, noninvasive ventilation, high-flow oxygen therapy, tracheostomy, cardiopulmonary resuscitation, bronchoscopy, placement of a ventilated patient in the prone position, introduction of a nasogastric tube, collection of respiratory samples by naso- or oropharyngeal swab, and respiratory kinesitherapy, among others," digestive endoscopy clearly fits "among others" [16].

A recent study by Chatterjee et al. [17] demonstrated that HCW who are exposed to the airways and oral cavities of patients for prolonged periods are at the greatest risk of infection.

Asymptomatic COVID-19 is an emerging and serious public health issue considering the high contagiousness of the disease. The concern of getting infected by SARS$\mathrm{CoV}-2$ in the workplace and subsequently transmitting the virus to family is a source of significant stress for endoscopy unit personnel. Several reports of screening of HCW for COVID-19 have highlighted the role of asymptomatic transmission of COVID-19 [18-20].

Reports from China indicate a high prevalence of mental health symptoms among the frontline HCW. The mental well-being of HCW has been largely neglected during this pandemic despite concerns raised by many $[21,22]$. Preprocedural testing has done much to decrease the palpable anxiety previously evident in endoscopy units and it has been a major step in improving the mental well-being of staff and patients. Recognizing these issues, many institutions have initiated a program of preprocedure COVID-19 testing for all patients undergoing endoscopic procedures. Routine screening prior to an elective procedure has been broadly discussed.

The putative benefits, i.e., identification of SARSCoV-2 carriers before a procedure to prevent further transmission (either to workers or to other patients present in the endoscopy unit), reduction of the consumption of resources and PPE, and improvement of hospital system efficiency, are intuitive. Prescreening of patients undergoing an elective endoscopy has been suggested by the American Society for Gastrointestinal Endoscopy (ASGE). The patients should be divided into 3 different categories, i.e., low, intermediate, or high risk, based on their history (contact with an individual positive for SARS-COV-2 or a history of travel to a high-risk country) and symptoms (fever, shortness of breath, cough, and diarrhea) [23]. Before arrival, each patient should be questioned about: fever, travel history (including all countries with a high incidence in COVID-19 transmission within 14 days prior to the endoscopy), occupational exposure (including HCW or laboratory staff handling COVID-19 specimens), contact history (in the last 14 days), and clustering, i.e., a methodology applied at our center before performance of any endoscopic procedure. In case of the presence of 1 of these 5 risk factors, the patient is considered a suspected case and a COVID-19 RT-PCR must be conducted prior to the endoscopic procedure [24].

To prevent transmission to care providers and others, appropriate infection control measures should be maintained for any patients with a possible exposure in the preceding 14 days, regardless of test results [25]. This is supported by the American Society of Anesthesiologists/ Anesthesia Patient Safety Foundation joint statement, which states: "because false negatives may occur with testing, droplet precautions should be used by operating room staff for operative cases. Before performing aerosolgenerating medical procedures, healthcare providers within the room should wear an N95 mask, eye protection, gown and gloves" [2].

Since most patients with COVID-19 have minimal symptoms or are asymptomatic, screening questions regarding travel history and the presence of symptoms are likely to miss the majority of positive patients. As a result, universal preprocedure screening may be the only way to prevent asymptomatic or presymptomatic patients from spreading the virus to other patients and $\mathrm{HCW}$, who themselves may be at a higher risk of severe disease from the virus [26]. It should be highlighted that a large number of patients in endoscopy units, including hospitalized ones, given their condition/pathology, are more vulnerable and they only use surgical masks.

However, there is discrepancy among recommendations published by international societies, especially with regard to the indication for preendoscopic virus testing and its consequences for the extent of PPE [27]. Also, some institutions may not have the capacity to realize a universal virus screening of all patients prior to an endo- 
scopic intervention. The cost-effectiveness of using preendoscopic testing and extensive PPE for all patients is at least questionable. Preprocedure testing has been adopted by several healthcare facilities around the world, with RT-PCR being the gold standard for testing. Antibody testing has not been proposed for preprocedure screening, as antibodies develop in the second week of symptoms and many COVID-19-infected patients never develop detectable antibodies $[28,29]$.

Regarding the value of a screening test, the sensitivity, specificity, and population prevalence of the target condition must be considered. Without a standard reference, measurement of RT-PCR sensitivity for SARS-CoV-2 in asymptomatic patients remains an unresolved problem [30]. As of June 7, 2020, clinical sensitivity has not been reported for any commercial tests in asymptomatic people. In the symptomatic cohort, considerable concern exists over false-negative results, ranging from 11 to $40 \%$ $[28,31]$. The probability of detecting SARS-CoV-2 also varies based on the time from exposure; it is as low as $0 \%$ in the immediate days following exposure, $33 \% 1$ day before symptom onset, and $62 \%$ on the day of symptom onset, and it peaks at $80 \%$ on day 3 of symptoms [32]. Prevalence varies widely depending on the characteristics of the population of interest. Highly variable testing accuracy and population characteristics will inevitably lead to false positives and false negatives.

Our institutional data from a low-prevalence region suggests that positivity for COVID-19 in asymptomatic patients undergoing endoscopic procedures is a rare event, detected in only 1 out of 167 tests. It is true that performing a preprocedure test gives us another level of security and allows decision making. Knowledge of the COVID-19 infection status allows nonurgent procedures to be postponed or urgent procedures to proceed with extra precautions in order to decrease the risk of transmission to hospital staff and other patients and families. As described in some articles, an additional benefit of testing might be the potentially decreasing use of elements of PPE which may be in short supply [22]. However, it is necessary to remember the high rate of false negatives in the asymptomatic period, which can be translated into a false sense of safety.

The education of trainees was another point of discussion. It has been significantly impacted by the pandemic, with many institutions excluding them from endoscopic procedures to minimize PPE use and increase the speed/ safety of procedures [22]. Once again, an important benefit of preprocedural testing is the increased likelihood of trainees being allowed to participate in procedures. Ac-

The Role of Preprocedure Screening of SARS-CoV-2 Infection cording to the current available data, a negative result is not $100 \%$ reliable and consequently the use of PPE is still needed. Taking this into account, it is necessary to evaluate the costs involved, and the usefulness of carrying out a preprocedure test, in asymptomatic patients when this might not change the way we work. As mentioned in other studies, the decision to perform a preprocedure test must be adapted to local prevalence [33-36]. Thus, in low-prevalence regions, preprocedure symptom screening of patients may arguably be an adequate measure for minimization of the risk of infection transmission. The benefits of testing seems to run parallel with disease prevalence. In low-prevalence areas with limited resources, clinical screening (symptoms, fever, and exposure) is necessary to increase the pretest probability and justify the costs of testing [36]. The vast majority of the population in a low-prevalence area, as in our case, will test negative. While a high negative predictive value sounds attractive, health systems are given no guidance on how to manage these negative test results. Can providers safely suspend measures for infection prevention and control? How should patients be instructed about their test results? The answers to these questions are critically important prior the implementation of widespread screening. Interpretation of negative RT-PCR screening must be considered in the context of its many limitations.

Lastly, rapid point-of-care tests have not yet been validated in asymptomatic patients, so delays from sample collection to results (up to 3 days in some institutions) can lead to false reassurance. Patients may test negative despite being in the early incubation phase. The viral load may increase in the time leading up to results [32].

Proceeding to endoscopic procedures without considering testing limitations could lead to devastating outcomes. Therefore, it is unclear whether testing will effectively minimize risk while reducing resource utilization and improving efficiency.

\section{Conclusion}

In summary, we found that $0.6 \%$ of patients coming for endoscopic procedures may be asymptomatic carriers of COVID-19. The chance of asymptomatic COVID-19 patients coming for elective endoscopic procedures may be reasonably high due to the high turnover of endoscopic procedures theatres. HCW and healthcare setups must be prepared and fully equipped to handle such situations in the near future, even after stabilization of the pandemic. 
SARS-CoV-2 preprocedure screening programs are being considered to improve patient and provider safety, outcomes, and resource management. Nevertheless, the putative benefits of screening with RT-PCR may not be achieved because of the low disease prevalence in some regions and poor test accuracy [37]. Further evidence and guidance are needed to manage both false-positive and false-negative results. In addition to testing, alternative strategies are required to combat the slowdown that the pandemic brought at endoscopic examinations.

After this work, we tried to respond to the needs by keeping the endoscopic activity within a new normal. We chose to perform an interview-based risk assessment in all patients, reserving the screening test for the dubious cases after the questionnaire and those performed under anesthetic sedation. There is consensus on the inclusion of these procedures in high-risk groups [15]. For all endoscopic examinations, adequate PPE is used to ensure the protection of health professionals and other patients.

\section{Statement of Ethics}

This study was done with approval from the institutional ethics committee and adhered to the tenets of the Helsinki Declaration.

\section{Conflict of Interest Statement}

The authors have no conflict of interests to declare.

Funding Sources

The authors received no financial support.

\section{Author Contributions}

The authors contributed equally to the writing of this paper.

\section{References}

1 Centers for Disease Control and Prevention. Cases \& deaths among healthcare personnel. Available from: https://covid.cdc.gov/coviddata-tracker/index.html\#health-care-personnel.

2 Tantau C, D KDWC, Erickson J, Madera ID, Chairman V, Loeffler C, et al. The ASA and APSF Joint Statement on Perioperative Testing for the COVID-19 Virus. Am Soc Anesthesiol Anesth Patient Saf Found. 2020;95814:13-5.

3 Bettencourt P, Fernandes C, Gil A, Almeida A, Alveolos M. Qualitative serology in patients recovered from SARS CoV 2 infection. J Infect. 2020;81(2):e120-1.

4 Sharma D, Agrawal V, Agarwal P. Roadmap for Restarting Elective Surgery During/After COVID-19 Pandemic. Indian J Surg. 2020 Jun;82(3):1-5.

5 Indian Council of Medical Research. Newer additional strategies for COVID-19 testing. New Delhi: Indian Council of Medical Research; 2020. p. 7.

6 Public Health Ontario. Updated IPAC Recommendations for Use of Personal Protective Equipment for Care of Individuals with Suspect or Confirmed. 2020;COVID-19:1-13.

7 European Centre for Disease Prevention and Control. COVID-19 infection prevention and control measures for primary care, including general practitioner practices, dental clinics and pharmacy settings: first update. Eur Cent Dis Prev Control. 2020;19:1-12.

8 European Centre for Disease Prevention and Controls. Heating, Ventilation and Air-Conditioning Systems In. Context (Ib). 2020;COVID-19:1-5.
9 Healthcare Sector, COVID-19 Outreach and Education Response, County of San Diego. COVID-19 Frequently Asked Questions (FAQs) for Dental Healthcare Professionals/ Personnel (DHCP). Live Well San Diego. 2021. p. 1-12.

10 Kowalski W. Health care facilities. In: Ultraviolet Germicidal Irradiation Handbook. Springer, Berlin, Heidelberg; 2009. doi: 10.1007/978-3-642-01999-9_17.

11 Atkinson J, Chartier Y, Lúcia Pessoa-Silva C, Jensen P, Li Y, Seto WH, et al. Natural ventilation for infection control in health-care settings. Geneva: World Heal Organization; 2016.

12 Direção Geral da Saúde. COVID-19: Abordagem do Doente com Suspeita ou Confirmação de COVID-19 - Norma 004. Lisbon; Direção Geral da Saúde; 2020.

13 Li Q, Guan X, Wu P, Wang X, Zhou L, Tong $\mathrm{Y}$, et al. Early Transmission Dynamics in Wuhan, China, of Novel Coronavirus-Infected Pneumonia. N Engl J Med. 2020 Mar;382(13): 1199-207.

14 DGS - Direção Geral da Saúde. Norma 019. COVID-19: Estratégia Nacional de Testes para SARS-CoV-2. Direção Geral Da Saúde. 2020;2020:1-14.

15 Jackson T, Deibert D, Wyatt G, DurandMoreau Q, Adisesh A, Khunti K, et al. Classification of aerosol-generating procedures: a rapid systematic review. BMJ Open Respir Res. 2020 Oct;7(1):1-9.
16 SPED; SPG; SPCP; Colégio da Especialidade de Gastrenterologia. Comunicado conjunto das Sociedades Portuguesas de Endoscopia Digestiva (SPED), Gastrenterologia (SPG) e Coloproctologia (SPCP) e do Colégio da Especialidade de Gastrenterologia da Ordem dos Médicos. Lisbon: SPED; 2020. p. 1-9.

17 Chatterjee P, Anand T, Singh KJ, Rasaily R, Singh R, Das S, et al. Healthcare workers \& SARS-CoV-2 infection in India: A case-control investigation in the time of COVID-19. Indian J Med Res. 2020;151:459-67.

18 Keeley AJ, Evans C, Colton H, Ankcorn M, Cope A, State A, et al. Roll-out of SARSCoV-2 testing for healthcare workers at a large NHS Foundation Trust in the United Kingdom, March 2020. Euro Surveill. 2020 Apr;25(14):1-4.

19 Steensels D, Oris E, Coninx L, Nuyens D, Delforge ML, Vermeersch P, et al. Hospital-Wide SARS-CoV-2 Antibody Screening in 3056 Staff in a Tertiary Center in Belgium. JAMA. 2020 Jul;324(2):195-7.

20 Padoan A, Cosma C, Sciacovelli L, Faggian D, Plebani M. Analytical performances of a chemiluminescence immunoassay for SARSCoV-2 IgM/IgG and antibody kinetics. Clin Chem Lab Med. 2020 Jun;58(7):1081-8.

21 Moraveji S, Thaker AM, Muthusamy VR, Banerjee S. Protocols, Personal Protective Equipment Use, and Psychological/Financial Stressors in Endoscopy Units During the COVID-19 Pandemic: A Large Survey of Hospital-Based and Ambulatory Endoscopy Centers in the United States. Gastroenterology. 2020 Oct;159(4):1568-70.e5. 
22 Ehrlich H, McKenney M, Elkbuli A. Protecting our healthcare workers during the $\mathrm{CO}$ VID-19 pandemic. Am J Emerg Med. 2020 Jul;38(7):1527-8.

23 Repici A, Maselli R, Colombo M, Gabbiadini R, Spadaccini M, Anderloni A, et al. Coronavirus (COVID-19) outbreak: what the department of endoscopy should know. Gastrointest Endosc. 2020 Jul;92(1):192-7.

24 Sinonquel P, Roelandt P, Demedts I, Van Gerven L, Vandenbriele C, Wilmer A, et al. COVID-19 and gastrointestinal endoscopy: what should be taken into account? Dig Endosc. 2020 Jul;32(5):723-31.

25 Livingston EH. Surgery in a Time of Uncertainty: A Need for Universal Respiratory Precautions in the Operating Room. JAMA. 2020 Jun;323(22):2254-5.

26 Hennessy B, Vicari J, Bernstein B, Chapman F, Khaykis I, Littenberg G. Guidance for resuming GI endoscopy and practice operations after the COVID-19 pandemic. Gastrointest Endosc. 2020 Sep;92(3):743-7.e1.

27 Gralnek IM, Hassan C, Beilenhoff U, Antonelli G, Ebigbo A, Pellisé M, et al. ESGE and ESGENA Position Statement on gastrointes- tinal endoscopy and COVID-19: an update on guidance during the post-lockdown phase and selected results from a membership survey. Endoscopy. 2020 Oct;52(10):891-8.

28 Huang $M$, Lu QB, Zhao H, Zhang Y, Sui Z, Fang $\mathrm{L}$, et al. Temporal antibody responses to SARS-CoV-2 in patients of coronavirus disease 2019. Cell Discov. 2020 Sep;6(1):64.

29 Okba N, Müller M, Li W, Wang C, GeurtsvanKessel C, Corman V, et al. SARS-CoV-2 specific antibody responses in COVID-19 patients. Emerg Infect Dis. medRXiv. 2020:118.

30 Woloshin S, Patel N, Kesselheim AS. False Negative Tests for SARS-CoV-2 Infectionchallenges and Implications. N Engl J Med. 2020 Aug;383(6):e38.

31 Arevalo-Rodriguez I, Buitrago-Garcia D, Simancas-Racines D, Zambrano-Achig P, del Campo R, Ciapponi A, et al. False-Negative Results of Initial Rt-Pcr Assays for Covid-19: a Systematic Review. PLoS One. 2020 Dec; 15(12):e0242958.

32 Kucirka LM, Lauer SA, Laeyendecker O, Boon D, Lessler J. Variation in False-Negative Rate of Reverse Transcriptase Polymerase
Chain Reaction-Based SARS-CoV-2 Tests by Time Since Exposure. Ann Intern Med. 2020 Aug;173(4):262-7.

33 Kenefick H, Lee J, Fleishman V. Improving physician adherence to clinical practice guidelines barriers and strategies for change. Cambridge: New England Healthcare Institute; 2008.

34 Nelson B. Unnecessary overuse of medical care causes both waste and harm. 2017. Available from: https://www.the-hospitalist.org/ hospitalist/article/122392/medical-careoveruse-causes-waste-harm-healthcare.

35 Norris SL, Holmer HK, Burda BU, Ogden LA, $\mathrm{Fu}$ R. Conflict of interest policies for organizations producing a large number of clinical practice guidelines. PLoS One. 2012;7(5): e37413.

36 Gupta S, Shahidi N, Gilroy N, Rex DK, Burgess NG, Bourke MJ. Proposal for the return to routine endoscopy during the COVID-19 pandemic. Gastrointest Endosc. 2020 Sep; 92(3):735-42.

37 Lother SA. Preoperative SARS-CoV-2 screening: can it really rule out COVID-19? Can J Anaesth. 2020 Oct;67(10):1321-6. 